Planta (Berl.) 98, 195-220 (1971)

(C) by Springer-Verlag 197I

\title{
A Model Describing Photosynthesis in Terms of Gas Diffusion and Enzyme Kinetics
}

\author{
Paul W. Lommen, Christa R. Schwintzer, C. S. Yocum* and David \\ M. GATES \\ Missouri Botanical Garden, St. Louis \\ Received January 10, 1971
}

Summary. A model predicting net photosynthesis of individual plant leaves for a variety of environmental conditions has been developed. It is based on an electrical analogue describing gas diffusion from the free atmosphere to the sites of $\mathrm{CO}_{2}$ fixation and a Michaelis-Menten equation deseribing $\mathrm{CO}_{2}$ fixation. The model is presented in two versions, a simplified form without respiration and a more complex form including respiration. Both versions include terms for light and temperature dependence of $\mathrm{CO}_{2}$ fixation and light control of stomatal resistance. The second version also includes terms for temperature, light, and oxygen dependence of respiration and $\mathrm{O}_{2}$ dependence of $\mathrm{CO}_{2}$ fixation.

The model is illustrated with curves based on representative values of the various environmental and biological parameters. These curves relate net photosynthesis to light intensity, $\left[\mathrm{CO}_{2}\right],\left[\mathrm{O}_{2}\right]$, temperature, and resistances to $\mathrm{CO}_{2}$ uptake. The shape of the $\left[\mathrm{CO}_{2}\right]$-net photosynthesis curves depends on the total diffusion resistance to $\mathrm{CO}_{2}$ uptake and the Michaelis constant for $\mathrm{CO}_{2}$ uptake. The curves range from typical Michaelis-Menten to Blackman types.

The model is combined with a model of leaf energy exchange permitting simultaneous estimation of net photosynthesis and transpiration. The combined model is illustrated with curves relating transpiration to photosynthesis under a wide variety of environmental conditions. Environmental regimes yielding maximum efficiency of water use are identified for the given assumptions and biologica] parameters.

\section{Introduction}

Net fixation of $\mathrm{CO}_{2}$ by plants is governed by a complex series of interactions of biological and environmental factors. These act on two basic processes, gas diffusion to the sites of carbon fixation and the biochemical processes of carbon fixation. We have developed a mathematical photosynthesis model for a leaf that combines descriptions of these basic processes and clearly shows the interaction between them. The model may be used by itself to help solve a variety of physiological problems. For example, it can be used to show the relative importance of any one factor, e.g. light intensity, in determining the rate of photo-

* On leave of absence from: Department of Botany, The University of Michigan, Ann Arbor, Michigan 48104, USA. 
synthesis under a given set of conditions. The model is combined with an equation describing the leaf energy budget to calculate the simultaneous rates of transpiration and photosynthesis for a given set of environmental conditions. This permits examination of a variety of ecologically important relationships. For example, the efficiency of water use (the ratio of photosynthesis to transpiration) can be estimated for any given set of biological and environmental conditions.

Two versions of the model are presented. First we give a simplified version for plants that do not respire in the light; later we give a somewhat more complex version including a respiratory source of $\mathrm{CO}_{2}$ for plants that respire in the light.

\section{The Model}

\section{A. Simplified Version for Leaves which do not Respire in Light}

Both this version and the standard version presented in the next section are based on two fundamental relationships. First, the physical process of $\mathrm{CO}_{2}$ diffusing from the atmosphere to the site of $\mathrm{CO}_{2}$ fixation in the chloroplast is described by Fick's Law:

$$
P=\frac{C_{A}-C_{C}}{R}
$$

where: $P$ is the photosynthetic rate $\left(\mathrm{nM} \mathrm{cm}^{-2} \mathrm{~s}^{-1}\right)^{*}$

$C_{A}$ is the $\left[\mathrm{CO}_{2}\right]$ in the air $\left(\mathrm{nM} \mathrm{cm}{ }^{-3}\right)$

$C_{C}$ is the $\left[\mathrm{CO}_{2}\right]$ in the chloroplasts $\left(\mathrm{nM} \mathrm{cm}{ }^{-3}\right)$

$R$ is the resistance to $\mathrm{CO}_{2}$ diffusion from the air through the leaf boundary layer, stomata, intercellular air spaces, cell walls and cytoplasm into the chloroplasts $\left(\mathrm{s} \mathrm{cm}^{-1}\right)$.

Second, the chemical process of $\mathrm{CO}_{2}$ fixation is described by an equation in the form of the Michaelis-Menten equation (M-M eq.) for the rate of an enzymatic reaction (this is not a true Michaelis-Menten case since a series of reactions is involved):

$$
P=\frac{P_{M}}{1+\frac{K}{C_{C}}}
$$

where: $P_{M}$ is the rate of photosynthesis $\left(\mathrm{nM} \mathrm{cm}^{-2} \mathrm{~s}^{-1}\right)$ at saturating $C_{C}$

$K$ is a constant equal to the chloroplast concentration of $\mathrm{CO}_{2}$ $\left(\mathrm{nM} \mathrm{cm}^{-3}\right)$ at which $P=P_{M} / 2$.

Eq. (1) is solved for $C_{C}$, substituted into Eq. (2), and the resulting quadratic equation solved for $P$. Thus,

\footnotetext{
* $\mathrm{nM}=$ nanomoles.
} 


$$
P=\frac{\left(C_{A}+K+R P_{M}\right)-\left[\left(C_{A}+K+R P_{M}\right)^{2}-4 C_{A} R P_{M}\right]^{\frac{1}{2}}}{2 R} .
$$

Mathematical details regarding this equation are in Appendix B. Further, using Eq. (3) it can be shown that

$$
\lim _{R \rightarrow \infty} P=\frac{C_{A}}{R}
$$

that is, at high values of resistance, every $\mathrm{CO}_{2}$ molecule reaching the chloroplasts is fixed so quickly that $C_{C}$ is essentially zero. Thus the rate of $\mathrm{CO}_{2}$ diffusion determines the photosynthetic rate for large $R$. Also,

$$
\lim _{R \rightarrow 0} P=\frac{P_{M}}{1+\frac{K}{C_{A}}}
$$

that is, at very low resistance the rate of photosynthesis is determined by the rate of the biochemical processes of $\mathrm{CO}_{2}$ fixation.

Thus if our assumptions are valid and the M-M eq. accurately describes the fixation of $\mathrm{CO}_{2}$ in the chloroplasts then Eq. (3) accurately describes the photosynthesis of a nonrespiring leaf in the light. Eq. (3) does not contain a term for dark respiration on the simplifying assumption that dark respiration is completely suppressed in the light even at low light intensities. Since it lacks a term for dark respiration, it can not be applied in the dark.

The maximum rate of photosynthesis $\left(P_{M}\right)$ is a function of light intensity and leaf temperature $(T)$. The light intensity dependence is described with another M-M eq. :

$$
P_{M}(L)=\frac{P_{M L}}{1+\frac{K_{L}}{L}}
$$

where: $P_{M L}$ is the value of $P_{M}$ at light saturation (nM $\mathrm{cm}^{-2} \mathrm{~s}^{-1}$ )

$L$ is the light intensity between 400 and $700 \mathrm{~nm}\left(\mathrm{erg} \mathrm{cm} \mathrm{cm}^{-2} \mathrm{~s}^{-1}\right)$

$K_{L}$ is the light intensity (erg $\mathrm{cm}^{-2} \mathrm{~s}^{-1}$ ) at which $P_{M}(L)=P_{M L} / 2$. The temperature dependence of $P_{M}$ has the same general characteristics as that of other biochemical processes. In Fig. 1 we show $G(T), G$ as a function of $T$, a temperature dependence of $P_{M}$ which we later use for illustration. It was adapted from the temperature dependence of net photosynthesis of a moss (Rastorfer and Higinbotham, 1968) after examination of the temperature dependence of net photosynthesis of a variety of plants including several vaseular plants (Raschke, 1970; Hofstra and Hesketh, 1969; Saitoh et al., 1970). Thus, we have for $L$ and $T$ dependencies of $P_{M}$

$$
P_{M}(L, T)=\frac{P_{M L T} G(T)}{1+\frac{K_{L}}{L}}
$$




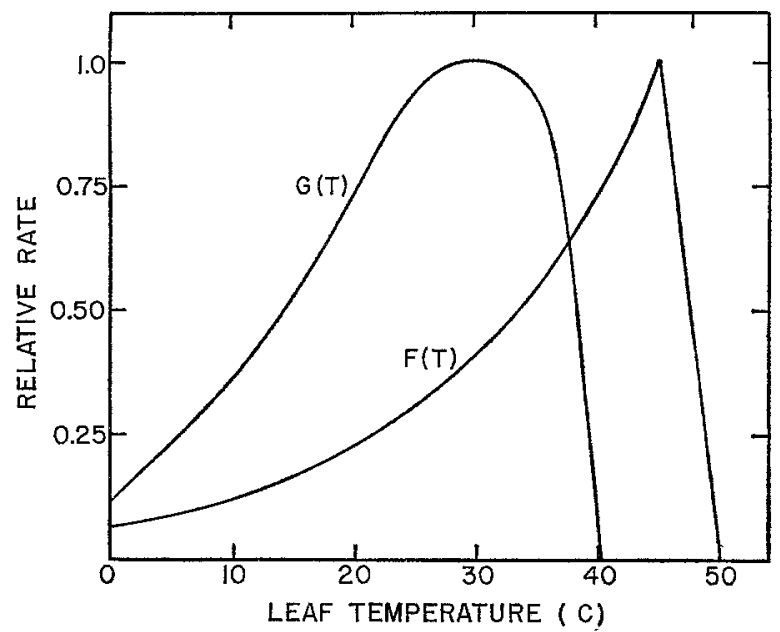

Fig. 1. Relative values of the maximum rate of photosynthesis, $G(T)$, and the maximum rate of dark respiration, $F(T)$, as functions of leaf temperature. The values are based on data in Figs. 1 and 2 of Rastorfer and Higinbotham (1968) for Bryum sandbergii at light intensities of $1.2 \times 10^{5} \mathrm{erg} \mathrm{cm}^{-2} \mathrm{~s}^{-1}$ (wavelength distribution not given) and $3.0 \% \mathrm{CO}_{2}$ in air. Values for dark respiration at $T>39^{\circ} \mathrm{C}$ are estimates

where: $P_{M L T}$ is the value of $P_{M}$ at saturation $L$ and optimum $T$ $\left(\mathrm{nM} \mathrm{cm} \mathrm{cm}^{-2} \mathrm{~s}^{-1}\right)$.

From the data of Gaastra (1959) $K_{L}$ is seen to be about $1 \times 10^{5} \mathrm{erg} \mathrm{cm}^{-2} \mathrm{~s}^{-1}$. The three forms of $P_{M}$ are related to each other as follows: $P_{M}$ is the maximim photosynthesis rate attainable at saturating $C_{C}$ and a given light intensity and temperature; $P_{M L}$ is the maximim rate attainable at saturing $C_{C}$ and saturating light at a given temperature; and $P_{M L T}$ is the maximum rate attainable by the leaf at saturating $C_{C}$, saturating light, and optimum temperature.

The temperature dependence of $K$ and $K_{L}$ is not at all certain. The value of $K$ is determined by the ratio of the sum of the rate constants of the two reactions leading to the disappearance of the enzyme-substrate complex and the rate constant for its formation (Briggs and Haldane, 1925) in one more steps of the $\mathrm{CO}_{2}$ reduction cycle. Each rate constant is expected to be temperature dependent. If their relative $T$ dependencies are the same, $K$ will be independent of $T$. Since data are not very complete on this, we will assume, for purposes of illustration at least, that $d K / d T=0$.

The value of $K_{L}$ is determined by the light reactions of photosynthesis and may be determined either by the photoacts or by the 

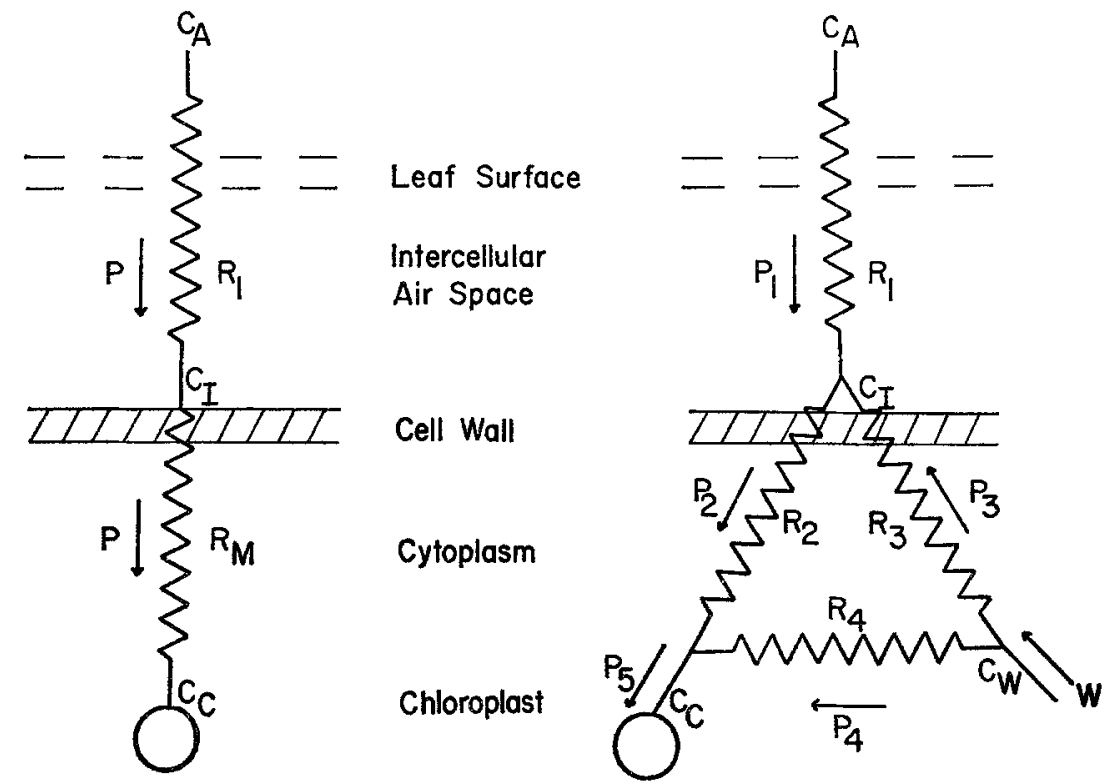

Fig. $2 \mathrm{~A}$ and $\mathrm{B}$. Electrical analogues of $\mathrm{CO}_{2}$ exchange in leaves. A. Simplified resistance network without a respiratory source of $\mathrm{CO}_{2}$. B. Standard resistance network including a respiratory source of $\mathrm{CO}_{2}$. Fluxes are taken as positive when they are in the directions indicated by the arrows. The $R$ 's are resistances, $P$ 's are $\mathrm{CO}_{2}$ fluxes, and $C$ 's are $\mathrm{CO}_{2}$ concentrations. All symbols are defined in Appen$\operatorname{dix} \mathbf{A}$

associated enzymatic steps. In the first case, it is temperature independent and in the latter the same arguments apply as in the case of $K$.

The resistance network in this version of the model is relatively simple as shown in Fig. $2 \mathrm{~A}$. The total resistance, $R$, is divided into two major components, $R_{1}$ and $R_{M}$. The component $R_{1}$ consists of the boundary layer resistance and the stomatal resistance while $R_{M}$ consists of all liquid phase resistances between the intercellular air spaces and the chloroplasts. The total resistance is affected by any factor which changes any of its components. Boundary layer resistance changes with wind speed, leaf size and leaf orientation (Vogel, 1970; Parkhurst et al., 1968; Raschke, 1956; Bange, 1953) and is taken as the boundary layer resistance to water vapor as shown in Eq. (16) multiplied by 1.56, the ratio of the diffusion coefficients for $\mathrm{H}_{2} \mathrm{O}$ and $\mathrm{CO}_{2}$ in air at $0^{\circ} \mathrm{C}$. 


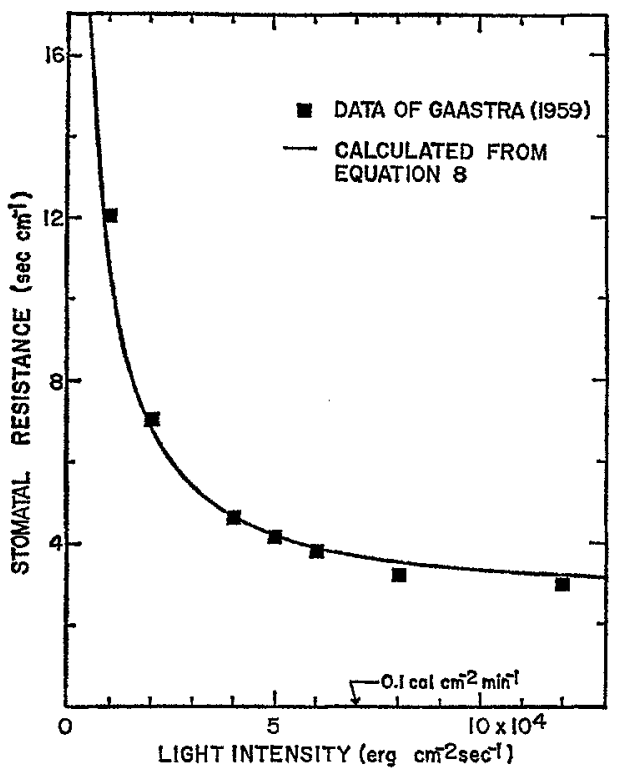

Fig. 3

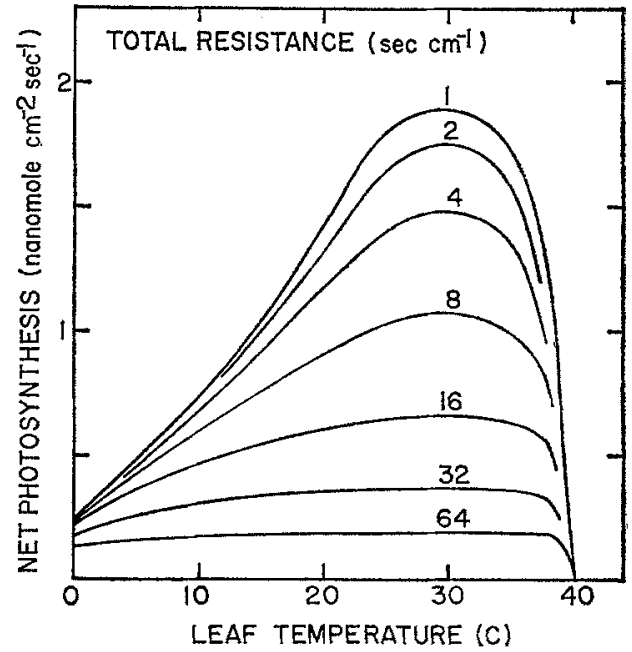

Fig. 4

Fig. 3. Stomatal resistance as a function of light intensity $(400-700 \mathrm{~nm})$. The data points were taken from Table 11 of Gaastra (1959) for turnip in $0.03 \% \mathrm{CO}_{2}$ and air temperature $20.3^{\circ} \mathrm{C}$. The solid line was calculated from Eq. (8) with $K_{R L}=$

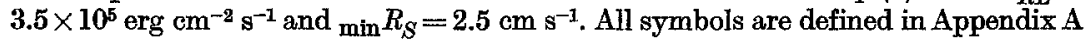

Fig. 4. Photosynthesis as a function of leaf temperature for several values of total $\mathrm{CO}_{2}$ diffusion resistance, $R$. The simplified model [Eq. (3)] was used with $C_{A}=$ $12.5 \mathrm{nM} \mathrm{cm}^{-3}$ (air concentration), $L=4 \times 10^{5} \mathrm{erg} \mathrm{cm}^{-2} \mathrm{~s}^{-1}$ (full sun), $K=10 \mathrm{nM} \mathrm{cm}^{-3}$, $T=30^{\circ} \mathrm{C}$ (optimum), and values of other parameters as listed in Appendix A.

All symbols are defined in Appendix A. $\left(5 \mathrm{nM} \mathrm{cm} \mathrm{cm}^{-2} \mathrm{~s}^{-1}=79 \mathrm{mg} \mathrm{dm}^{-2} \mathrm{hr}^{-1}\right)$

Stomatal resistance, $R_{S}$, is also known to change (Meidner and Mansfield, 1968; Zelitch, 1969). It changes with $L$, leaf water potential, the phase of the endogenous rhythm, $T$, and $\left[\mathrm{CO}_{2}\right]$. In the absence of water stress, light intensity is probably the single most important factor determining stomatal aperture. Following Waggoner (1969) we use an inverted M-M type equation:

$$
R_{S}=\frac{L+K_{R L}}{L} \min R_{S}
$$

where: $\min _{S} R_{S}$ is the minimum value of $R_{S}$ reached at high light intensities $\left(\mathrm{cm} \mathrm{s}^{-1}\right)$

$K_{R L}$ is the value of $L$ such that $R_{S}=2\left(\min R_{S}\right)\left(\mathrm{erg} \mathrm{cm}^{-2} \mathrm{~s}^{-1}\right)$. 
Eq. (8) is graphed in Fig. 3 along with values of $R_{S}$ observed in turnip (Gaastra, 1959). Leaf water potential is a function of several environmental factors and is very difficult to predict. The phase of the endogenous rhythm of most plants favors under natural conditions stomatal opening during the daylight hours. In the illustrations we have assumed that both the water potential and the endogenous rhythm favor full stomatal opening. Reports on the effect of temperature on steady-state stomatal apertures are contradictory (Meidner and Mansfield, 1968). However, in some species at least, e.g. Zea mays, stomatal diffusion resistance is significantly affected by temperature (Raschke, 1970). The nature of the effect of $\left[\mathrm{CO}_{2}\right]$ on stomatal apertures is unclear (Meidner and Mansfield, 1968; Zelitch, 1969). However, there is considerable evidence that at relatively low $\mathrm{CO}_{2}$ levels the stomatal aperture increases with decreasing $\left[\mathrm{CO}_{2}\right]$ (Meidner and Mansfield, 1968). For simplicity no $\left[\mathrm{CO}_{2}\right]$ and $T$ dependencies of $R_{S}$ have been included in the illustrations at this time since the quatitative nature of these relationships is still relatively unclear.

As more information becomes available many of the estimates made in the above two paragraphs concerning the effects of environmental conditions on $P_{M}, K$ and $R$ can be refined and additional terms, e.g. $\left[\mathrm{CO}_{2}\right]$ and $T$ dependencies of $R_{S}$, can be put into the model in order to more accurately describe photosynthesis.

To illustrate what has been discussed so far, photosynthesis as a function of several variables is shown in Figs. 4, 5, and 6. In Fig. 4, the variation of photosynthesis with $T$ is shown for several values of $R$. It is evident that when the resistance is high, photosynthesis depends almost entirely on the rate of diffusion and is nearly independent of temperature, as predicted by Eq. (4).

In Fig. 5, the effect of changing $K$ is shown on a plot of $P$ versus $C_{A}$. Fig. 6 is similar to Fig. 5 except that $R$ is changing instead of $K$. In both cases when $\frac{R P_{M}}{K} \gg 1$ a Blackman (1911) curve is approached, and when $\frac{R P_{M}}{K} \ll 1$ a Michaelis-Menten curve is approached. Blackman curves, which are characterized by two linear portions connected by a sharp elbow, result when the resistance to $\mathrm{CO}_{2}$ uptake controls the rate of photosynthesis. Resistance is controlling when $K$ is very small or $R$ is large. Michaelis-Menten curves result when biochemical reactions control the rate of photosynthesis. This occurs either at large $K$ or very small $R$.

\section{B. Standard Version for Leaves which Respire in Light}

Since most and possibly all plants respire in light it is necessary to add respiration to the simple model presented in Section A. Fig. 2 


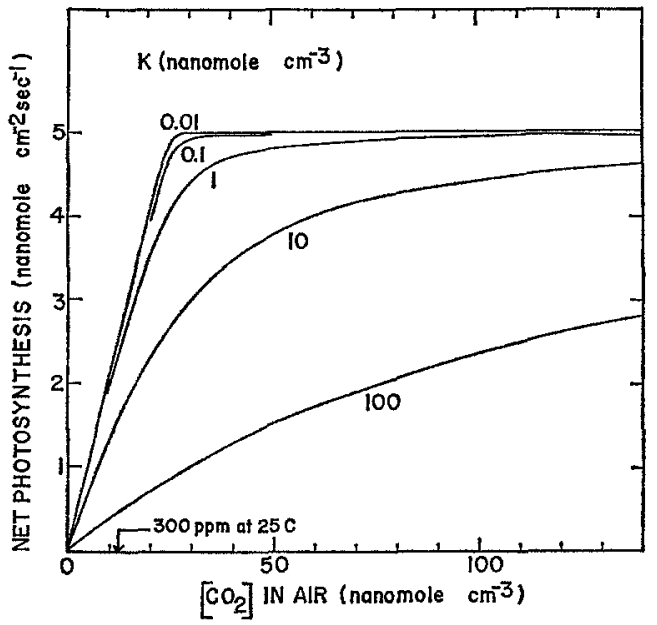

Fig. 5. Photosynthesis as a function of the $\mathrm{CO}_{2}$ concentration in the air for several values of the Michaelis constant, $K$. The simplified model [Eq. (3)] was used with $R=5 \mathrm{~s} \mathrm{~cm}^{-1}, T=30^{\circ} \mathrm{C}$ (optimum), $L=4 \times 10^{5} \mathrm{erg} \mathrm{cm}^{-2} \mathrm{~s}^{-1}$ (full sun), and values of other parameters as listed in Appendix A. All symbols are defined in Appendix A

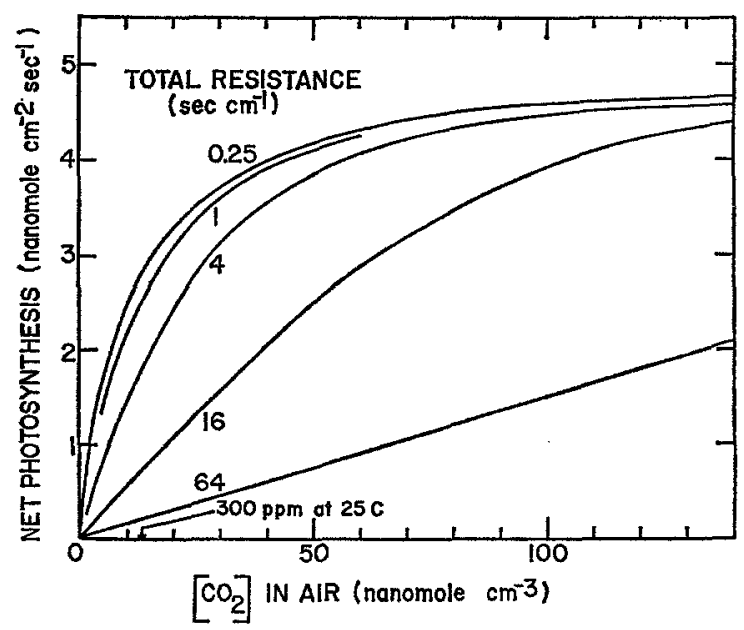

Fig. 6. Photosynthesis as a function of $\mathrm{CO}_{2}$ concentration in the air for several values of total $\mathrm{CO}_{2}$ diffusion resistance, $R$. The simplified model [Eq. (3)] was used with $K=10 \mathrm{nM} \mathrm{cm}{ }^{-3}, T=30^{\circ} \mathrm{C}$ (optimum), $L=4 \times 10^{5} \mathrm{erg} \mathrm{cm}^{-2} \mathrm{~s}^{-1}$ (full sun), and values of other parameters as listed in Appendix A. All symbols are defined in Appendix A 
compares diagramatically the version of the model presented in Section $\mathbf{A}$ with the one we will now describe. Two differences are apparent: 1) a flux of $\mathrm{CO}_{2}$ produced by respiration, $W$, is included, and 2) the resistance network (from Lake, 1967) is necessarily more complex.

Resistance $R_{1}$ is the resistance between the outside air and the intercellular air spaces (IAS), and is comprised of boundary layer and stomatal resistances. The $\left[\mathrm{CO}_{2}\right]$ is assumed to be uniform throughout the IAS. Resistances $R_{2}$ and $R_{3}$ are the direct resistances between the IAS and the sites of photosynthesis and respiration, respectively, and both presumably contain cell wall and cytoplasm path-resistances. Finally, $R_{4}$ is the direct resistance between the sites of respiration and the chloroplasts. The indirect diffusion paths from the IAS to the chloroplasts are represented by $R_{3}+R_{4}$. Thus, the net diffusive resistance "seen" by a $\mathrm{CO}_{2}$ molecule between the IAS and the chloroplasts is $R_{2}$ in parallel with $\left(R_{3}+R_{4}\right)$. Similar situations exist for the total resistances between the IAS and the sites of respiration, and between the sites of respiration and the chloroplasts. This triangle of resistances may seem to present more complications than necessary. This is discussed later. Compared with any real leaf, however, it is a great simplification. Also, to describe paths as direct or indirect is not completely satisfactory but is not avoidable in an electrical analogue with discrete circuit elements.

Proceeding as before we derive an exact expression for net photosynthesis as a function of $P_{M}, K$, the $R$ 's, $W$ and $C_{A}$ :

$P_{1}=$ net photosynthesis

$$
\begin{array}{r}
=\left[C_{A}+K+S_{1}\left(P_{M}-W\right)-W S_{2}\right]-\left\{\left[C_{A}+K+S_{1}\left(P_{M}-W\right)-W S_{2}\right]^{2}\right. \\
2 S_{1} \\
\frac{\left.-4 S_{1}\left[\left(C_{A}-W S_{2}\right)\left(P_{M}-W\right)-W K\right]\right\}^{\frac{1}{2}}}{2 S_{1}}
\end{array}
$$

where the only new symbols introduced are $S_{1}$ and $S_{2}$, both having units of resistance:

$$
\begin{aligned}
S_{1} & \equiv R_{1}+\frac{R_{2}\left(R_{3}+R_{4}\right)}{R_{2}+R_{3}+R_{4}}, \\
S_{2} & \equiv \frac{R_{2} R_{4}}{R_{2}+R_{3}+R_{4}} .
\end{aligned}
$$

Mathematical details are given in Appendix C. Also in Appendix C are expressions for the $\left[\mathrm{CO}_{2}\right]$ at the three resistance junctions inside the leaf. Environmental factors affecting $K$ and $R_{1}$ were discussed in Section A.

Respiratory $\mathrm{CO}_{2}$ produced in photosynthetic tissue during illumination has several sources. Following the terminology of Jackson and 
Volk (1970), we use "mitochondrial respiration" $\left(W_{M}\right)$ to refer to the sum of the classical dark respiratory pathways and "peroxisomal respiration" $\left(W_{P}\right)$ to refer to the sum of the light-induced pathways the bulk of which involves glycolate metabolism. Consequently, $W=W_{M}+W_{P}$.

Mitochondrial respiration is probably almost completely suppressed in the light except at low light intensities (Hew et al., 1969; Forrester et al., 1966; Hoch et al., 1963; Irvine, 1970; Holmgren and Jarvis, 1967). Irvine (1970) measured the rate of respiration at various light intensities in sugar cane, a low compensation species, with an isotope method using a labeling sequence capable of measuring most of $W_{M}$ but little if any $W_{P}$. Measured respiration declined sharply with increasing light intensity until it reached a very low rate at light intensities greater than one-fourth of full sunlight. This relationship, as approximated by the exponential component of Eq. (12), is used to describe the dependence of $W_{M}$ on light intensity. The temperature dependence of $W_{M}, F(T)$, is well known. That used, is shown in Fig. 1. It is taken from the data of Rastorfer and Higinbotham (1968) for the same moss used for $G(T)$ for $T=4-39^{\circ} \mathrm{C}$ and is estimated for $T<4^{\circ} \mathrm{C}$ and $T>39^{\circ} \mathrm{C}$. Mitochondrial respiration is independent of $C_{A}$ and $C_{O A}$ (the $\mathrm{O}_{2}$ concentration in the air expressed as a fraction $(V / V)$, Forrester et al., 1966); hence no $C_{A}$ and no $C_{O A}$ dependence is included in the description of $W_{M}$. Thus

$$
W_{M}=W_{M L T}\left\{\exp \left[(-\ln 2)\left(\frac{L}{L_{H}}\right)\right]\right\} F^{\prime}(T)
$$

where: $W_{M L T}\left(\mathrm{nM} \mathrm{cm}^{-2} \mathrm{~s}^{-1}\right)$ is the value of $W_{M}$ at zero $L$ and optimum $T\left(45^{\circ} \mathrm{C}\right)$

$L_{H}\left(\mathrm{erg} \mathrm{cm}^{-2} \mathrm{~s}^{-1}\right) \quad$ is a constant such that when $L=L_{H}$, $\exp \left[(-\ln 2)\left(\frac{L}{L_{H}}\right)\right]=1 / 2$

$F(T)$ is a temperature dependence of $W_{M}$.

There is doubt about the extent of $W_{P}$ since its precise value is impossible to determine with the existing indirect methods of measurement (Jackson and Volk, 1970). However, it can be shown that $W_{P}$ increases with increasing light intensity (Jackson and Volk, 1970; Holmgren and Jarvis, 1967; Hew et al., 1969; Decker, 1959), that its temperature dependence probably follows that of photosynthesis (Hofstra and Hesketh, 1969), except possibly at temperatures greater than the photosynthetic optimum (Jackson and Volk, 1970), that it increases with increasing $C_{O A}$ (Forrester et al., 1966; Tregunna et al., 1966; Fock and Egle, 1966; Jackson and Volk, 1970), and that the effect of $C_{O A}$ is governed by an interaction between $C_{O A}$ and $C_{A}$ (Jackson and Volk, 1970; Fock and Egle, 1966; Ellyard and Gibbs, 1969). For purposes of 
jllustration the following light, temperature, and $C_{O A}$ dependencies will be used. No $C_{A}$ dependence is included. These dependencies can be refined and a $C_{A}$ dependency added as more information becomes available. The light dependence is taken to have the familiar M-M form with $K_{W P L}$, the M-M constant for the reaction having about the same value as $K_{L}$, the M-M constant for the light dependence of $P_{M}$. The temperature dependence is taken to be proportional to $G(T)$ (Fig. 1). The $O_{O A}$ dependence is taken to increase linearly with $C_{O A}$ since the $\mathrm{CO}_{2}$ compensation concentration $(\Gamma)$ is linearly dependent on $C_{O A}$ (Forrester et al., 1966). Thus

$$
W_{P}=\frac{W_{P L T O} C_{O A} G(T)}{1+\frac{K_{W P L}}{L}}
$$

where $W_{P L T O}\left(\mathrm{nM} \mathrm{cm}^{-2} \mathrm{~s}^{-1}\right)$ is the value of $W_{P}$ at saturating $L$, optimum $T$, and $C_{O A}=1.0$.

Oxygen probably influences photosynthesis in a variety of ways (Turner and Brittain, 1962). In addition to its previously mentioned effect on $W_{P}$, it may also have a variety of effects on the dark and light reactions of photosynthesis. $\mathrm{O}_{2}$ competitively inhibits ribulose-diphosphate carboxylase with respect to $\mathrm{CO}_{2}$ (Bowes and Ogren, 1970). The relative importance of this effect is not known and consequently no description is included in the model at this time. It is likely that $C_{O A}$ also influences $P_{M}$. As $O_{O A}$ increases $P_{M}$ probably decreases since significant amounts of Calvin-cycle compounds appear to be shunted into the glycolate pathway at high $C_{O A}$ (Ellyard and Gibbs, 1969) and the degree of inhibition of photosynthesis by $\mathrm{O}_{2}$ at constant $C_{A}$ and saturating $L$ increases with increasing $C_{O A}$ (Björkman, 1966). The form of the dependence of $P_{M}$ on $C_{O A}$ is not yet clear to us. For a convenient first approximation in the illustrations to follow we will assume a linear dependence such that if

( $M$ is dimensionless), then

$$
\frac{\left(W_{P I I O}\right) C_{O A}}{P_{M L T}}=M
$$

$$
P_{M}\left(L, T, C_{O A}\right)=\left[P_{M}(L, T)\right](1-M) .
$$

$\mathrm{O}_{2}$ may have additional effects on photosynthesis. These can be included in the model as their nature becomes clearer.

To illustrate this photosynthesis model for photorespiring plants $\left(\mathrm{C}_{3}\right.$ or high-compensation plants), Figs. 7 through 9 are given. Fig. 7 shows $P_{1}$, net photosynthesis, versus $P_{A}$ for 5 different values of $C_{O A}$. The inhibition of net photosynthesis with increasing $C_{O A}$ is clearly shown in this figure. The reasons are twofold (and nearly impossible to 


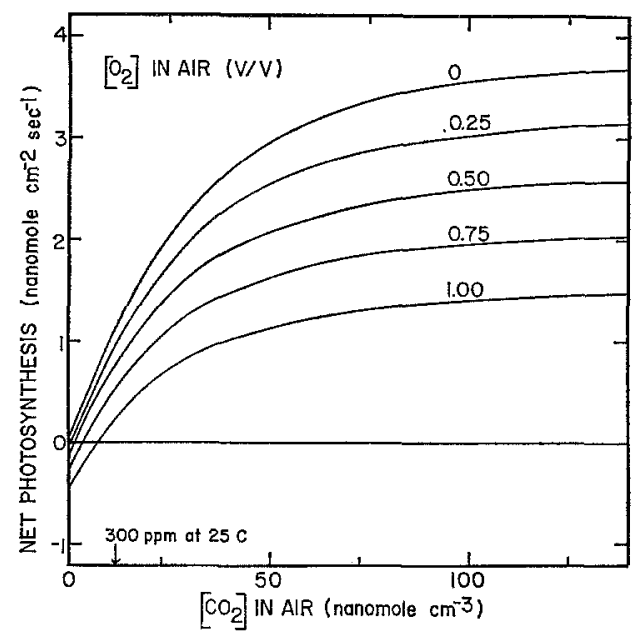

Fig. 7. Net photosynthesis as a function of $\mathrm{CO}_{2}$ concentration in the air for several values of $\mathrm{O}_{2}$ concentration in the air. The standard model [Eq. (9)] was used with values in Appendix A

separate from each other in the figure): 1) increased recycling of $\mathrm{CO}_{2}$ inside the leaf due to the increase of $W$ with increasing $C_{O A}$ causes less $\mathrm{CO}_{2}$ to be taken from the air, and 2) decreased $P_{M}$ with increased $C_{O A}$ invariably causes a decrease in gross photosynthesis and, consequently, net photosynthesis. Note that $\Gamma$ increases with increasing $C_{O A}$. Increasing $\Gamma$ with increasing $C_{O A}$ has also been observed experimentally (Forrester et al., 1966).

Fig. 8 shows $P_{1}$ versus $L$. Note that the light compensation-point decreases with increasing $C_{A}$ as has been observed experimentally (Heath, 1969). The final example here, Fig. 9, shows $P_{1}$ versus $C_{A}$ and $C_{C}$ versus $C_{A}$ for several values of $K$. The effect of respiration on the $P_{1}$ versus $C_{A}$ curves is shown by comparing Figs. $9 \mathrm{~A}$ and 5 . Note that the curves resemble each other closely but that respiration lowers the maximum rates of net photosynthesis and results in negative net photosynthesis at low $C_{A}$. It is often assumed that $C_{C} \cong 0$ under optimum conditions of light and temperature, but Fig. $9 \mathrm{~B}$ shows this is a reasonable assumption only when $C_{A}<R P_{M}$ and $\frac{R P_{M}}{K} \gg 1$. Note that in Blackman curves $C_{A}=R P_{M}$ at the elbow.

It is now appropriate to make a few additional comments about this version of the model. First, the magnitude of $W$ is difficult to measure because of recycling within the leaf. This is discussed in some 


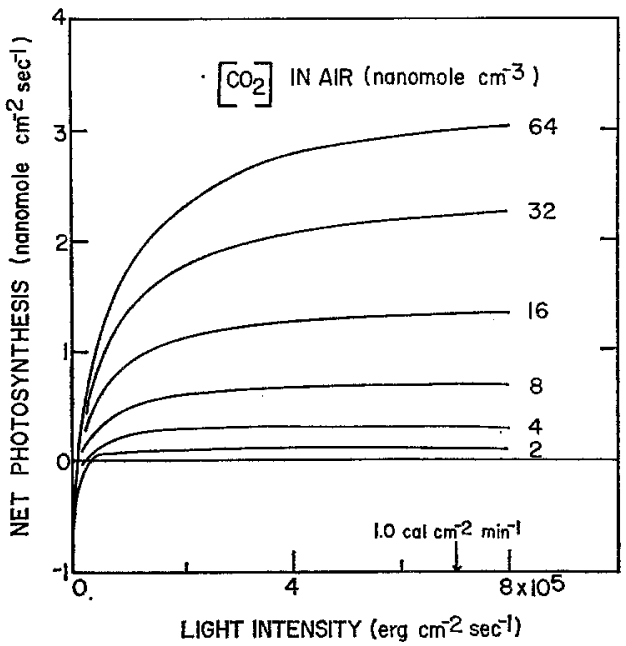

Fig. 8. Net photosynthesis as a function of light intensity for several values of $\mathrm{CO}_{2}$ concentration in the air. The standard model [Eq. (9)] was used with values in Appendix A

detail by Samish and Koller (1968) and by Lake (1967) who give three methods (all of which can be shown to be mathematically and experimentally equivalent) of estimating $W$ from the behavior of $P_{1}$ for $C_{A}$ in the range 0 to $\Gamma$. This method is a distinct improvement over the earlier practice of estimating $W$ by the value of net photosynthesis at zero $C_{A}$, but it assumes $\left[\mathrm{CO}_{2}\right]$ at the chloroplasts is zero, which is equivalent to assuming $K=0$, and it can easily be shown to give an underestimate of $W$ which gets worse as $K$ increases.

Samish and Koller (1968) raise two objections against Lake's model, which contains the same resistance network as ours, and which therefore deserve comment. First is the objection that we imply these resistances are separate and discrete. This is not the case, as seen earlier when we mention resistances represent "direct" or "indirect" paths and that the resulting complication is the penalty for including the possibilities we want and remaining with the electrical analogue. Second, the objection that we should not mathematically put three resistances where we cannot even measure one very well, is valid and can be answered only after a thorough experimental test of the model.

A reasonable assumption when testing this model is $R_{2}=R_{3}$. Since the sites of both respiration and photosynthesis are located in the relatively thin layer of cytoplasm near the cell wall the diffusion paths represented by $R_{2}$ and $R_{3}$ are of similar length and $R_{4}<R_{2}$ since $R_{4}$ 

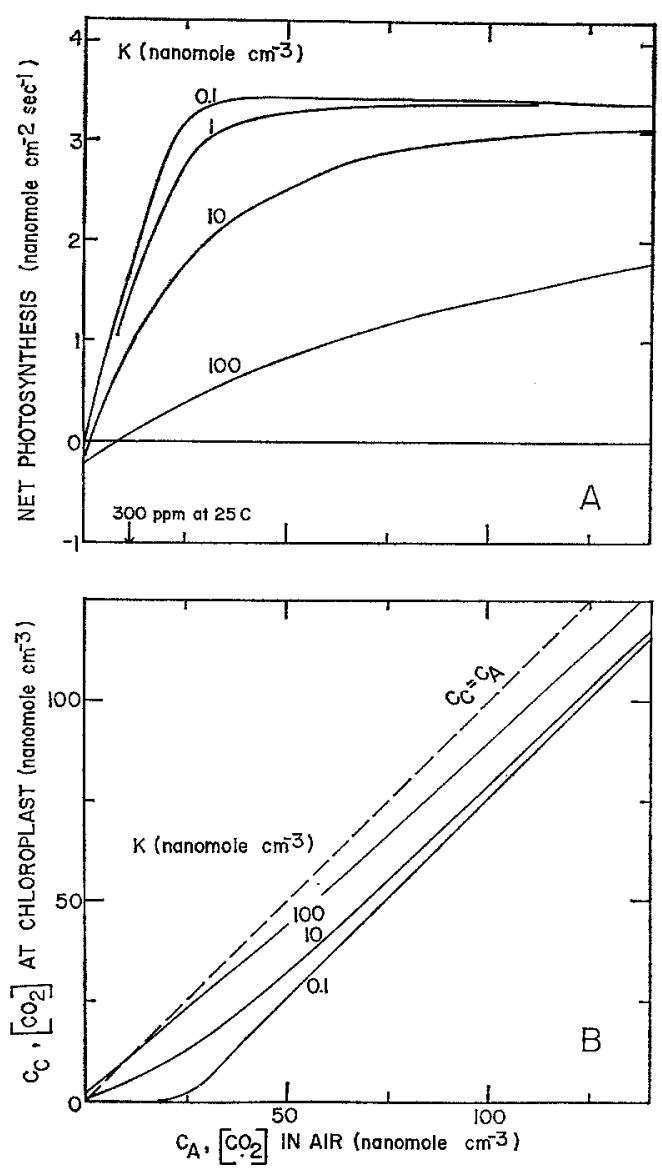

Fig. 9. A. Net photosynthesis as a function of $\mathrm{CO}_{2}$ concentration in the air for sereral values of $K$. B. $\mathrm{CO}_{2}$ concentration in the chloroplasts as a function of $\mathrm{CO}_{2}$ concentration in the air for several values of $K$. The standard model [Eq. (9)] was used with values in Appendix A. All symbols are defined in Appendix A

does not contain a cell wall component and the chloroplasts and peroxisomes are often in close proximity (Frederick and Newcomb, 1969). (It was this reasoning which determined the choices of $R_{2}, R_{3}$ and $R_{4}$ in the examples illustrated.) The triangle of resistances formed by $R_{2}$, $R_{3}$ and $R_{4}$ may not cause as much complication as appears at first glance and may provide considerable latitude for interpreting photosynthesis data. Consider, for example, Samish and Koller's (1968) calculated values of $r_{p}$ (their notation) a resistance which closely corresponds to $R_{2}$ in parallel with $\left(R_{3}+R_{4}\right)$, hereafter $R_{2} / /\left(R_{3}+R_{4}\right)$. If, 
as suggested above, $R_{2} \cong R_{3}$ and $R_{4}<R_{2}$ then $R_{2} / /\left(R_{3}+R_{4}\right) \cong R_{2} / / R_{3} \cong$ $R_{2} / 2$. Consequently, if $R_{2} / /\left(R_{3}+R_{4}\right)$ can be measured then $R_{2}$ and $R_{3}$ can be closely approximated.

\section{Combining the Photosynthesis Model with the Leaf Energy Budget}

Environmental conditions affect photosynthesis not only directly as seen in the photosynthesis model but also indirectly through their effects on leaf temperature. Leaf temperature is determined by energy exchange between the leaf and its environment and depends on several properties of the leaf as well as environmental conditions. The leaf energy budget describes the relationships between leaf properties, environmental conditions, transpiration, and leaf temperature (Gates, 1968). It can be combined with the photosynthesis model to first calculate leaf temperature and transpiration and then photosynthesis (Gates et al., 1969). The combined models are useful in evaluating the effects of wind speed, air temperature, relative humidity, incident radiation, $\mathrm{CO}_{2}$ concentration, and leaf properties on both transpiration and photosynthesis.

The energy budget concept is straightforward: for a leaf in steadystate conditions its temperature is such that energy gained by the leaf equals the energy lost. The energy budget of a single leaf is expressed as follows (Gates, 1968):

$Q_{A B S}=R A D+C+L_{v} E$

or

$Q_{A B S}=\varepsilon \sigma(T+273)^{4}+K_{1}\left(\frac{V}{D}\right)^{\frac{1}{2}}\left(T-T_{A}\right)+L_{v} \frac{d(T)-\text { r.h. } d\left(T_{A}\right)}{r_{s}+K_{2} \frac{B^{0.20} D^{0.35}}{V^{0.55}}}$

where: $Q_{A B S}$ is the absorbed radiation $\left(\mathrm{erg} \mathrm{cm}^{-2} \mathrm{~s}^{-1}\right)$

$R A D$ is radiation emitted (erg $\mathrm{cm}^{-2} \mathrm{~s}^{-1}$ )

$C \quad$ is convective heat transfer $\left(\mathrm{erg} \mathrm{cm}^{-2} \mathrm{~s}^{-1}\right)$

$L_{v} \quad$ is the latent heat of vaporization of water (erg $\mathrm{nM}^{-1}$ )

$E \quad$ is transpiration (nM cm-2 $\mathrm{s}^{-1}$ )

$\varepsilon \quad$ is the emissivity $(=0.95)$

$\sigma \quad$ is the Stefan-Boltzmann constant $=5.67 \times 10^{-5} \mathrm{erg} \mathrm{cm}^{-2} \mathrm{~s}^{-1}$ ${ }^{\circ} \mathrm{K}^{-4}\left(T\right.$ in ${ }^{\circ} \mathrm{C}+273=T$ in $\left.{ }^{\circ} \mathrm{K}\right)$

$K_{1}$ is an empirically determined convection coefficient and $=1.13 \times 10^{4}$ for $B \leqslant D$ or $B=D \leqq 5 \mathrm{~cm}$ and $=7.0 \times 10^{3}$ for $B \gg D$ or $B=D>5 \mathrm{~cm}$

$T_{A} \quad$ is the air temperature $\left({ }^{\circ} \mathrm{C}\right)$

$V \quad$ is the wind speed $\left(\mathrm{cm} \mathrm{s}^{-1}\right)$

$D$ is the leaf dimension along wind flow (cm)

$B$ is the leaf dimension perpendicular to wind flow (cm) 
$d(T)$ and $d\left(T_{A}\right)$ are the saturation densities of water vapor at $T$ and $T_{A}$ respectively $\left(\mathrm{nM} \mathrm{\textrm {cm } ^ { - 3 } )}\right.$

r.h. is the relative humidity expressed as a number between 0 and 1

$r_{s}$ is the stomatal diffusion resistance to water vapor $\left(\mathrm{s} \mathrm{cm}^{-1}\right)$ $K_{2} \frac{B^{0.20} D^{0.35}}{V^{0.55}}$ is the boundary layer resistance to water vapor $\left(\mathrm{s} \mathrm{cm}^{-1}\right.$ ) where $K_{2}$ is another empirically determined constant $=1.56$ for $B \ll D$ or $B=D \leqq 5 \mathrm{~cm}$ and 2.10 for $B \gg D$ or $B=D>5 \mathrm{~cm}$.

The radiation absorbed by the leaf $\left(Q_{A B S}\right)$ consists of both long$(>4 \mu \mathrm{m})$ and short- $(<4 \mu \mathrm{m})$ wave radiation. It depends on the leaf area exposed, the spectral absorptivity of the leaf, and the incident flux. Thus

$$
A Q_{A B S}=\alpha_{S} A_{S} I_{S}+\alpha_{L} A_{L} I_{L}
$$

where $\alpha_{S}$, the short-wave absorptivity, is taken as 0.50 (Gates, 1965); $\alpha_{L}$, the long-wave absorptivity, is 0.95 (Gates and Tantraporn, 1952); $A$ is the total surface area of the leaf; $A_{S}$ and $A_{L}$ are the areas exposed to short-wave incident flux, $I_{S}$, and long-wave incident flux, $I_{L}$, respectively. In the illustrations $Q_{A B S}$ is calculated with the following simplifying assumptions: a) the leaf is horizontal and located at the top of the canopy in such a way that the upper surface "sees" only sky and the sun and the lower surface "sees" only leaves and stems in the canopy interior, b) the temperature of the canopy interior is $T_{A}$ and its emissivity is 0.95 , c) no solar radiation is reflected to either leaf surface, and d) the skies are clear. Under these conditions the entire upper surface receives both shortand long-wave radiation, while the entire lower surface receives only long-wave radiation. The short-wave radiation incident on the upper surface $\left(I_{S}\right)$ is taken from pyranometer measurements; and the long-wave radiation incident on the upper and lower surfaces is calculated from $T_{A}$ with Swinbank's (1963) formula and the Stefan-Boltzmann law, respectively. Hence

$$
\begin{aligned}
Q_{A B S}= & \frac{1}{2}\left\{0.50\left(I_{S}\right)+0.95\left[5.31 \times 10^{-10}\left(T_{A}+273\right)^{6}\right]\right. \\
& \left.+0.95\left(T_{A}+273\right)^{4}\right\} .
\end{aligned}
$$

Transpiration $(E)$ and $P_{1}$ are obtained simultaneously as follows. The desired environmental conditions and plant parameters are entered into Eq. (16) which is solved for $E$ and $T$. The leaf temperature $(T)$ is then entered into the photosynthesis model along with $L$ to obtain $P_{1}$. The light intensity $(L)$ is taken as $0.45 I_{S}$ (Anderson, 1967) for direct and scattered sunlight. 


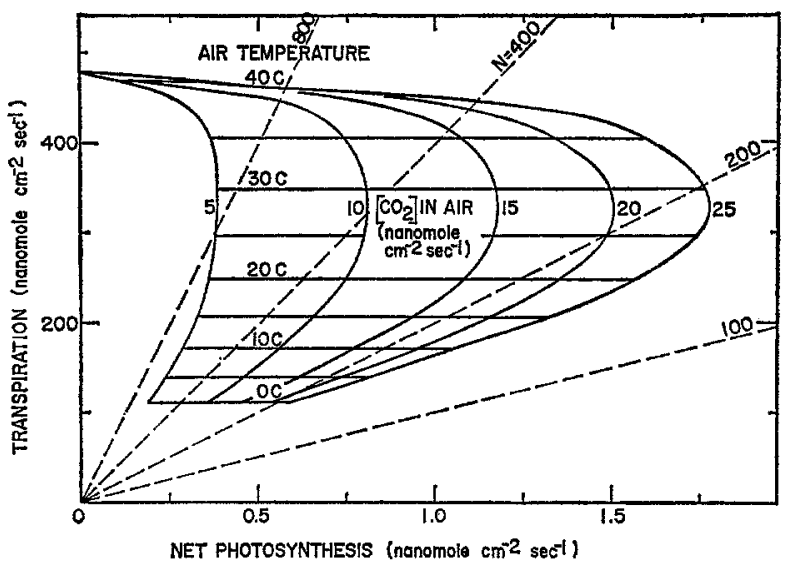

Fig. 10. Transpiration and net photosynthesis as functions of air temperature and $\mathrm{CO}_{2}$ concentration in the air. The transpiration-assimilation ratio, $N$, is the number of molecules of $\mathrm{H}_{2} \mathrm{O}$ transpired per molecule of $\mathrm{CO}_{2}$ fixed. The energy budget [Eq. (16)] and the standard model [Eq. (9)] were used with values in Appendix A

Figs. 10-12 illustrate some of the descriptive and predictive capacity of the combined photosynthesis model and energy budget. They suggest the general nature of the various relationships and important areas of experimentation. The details of these figures and their interpretation are presented for illustration only. They are based on biological param. eters derived from several different plants. In addition some aspects of the photosynthesis model, e.g. environmental effects on stomatal aperture, may need further refinement after more experimental evidence is accumulated. Values of $N$, the transpiration-assimilation ratio, are indicated in Figs. 10 and 12 and plotted in Fig. 11 D. The transpirationassimilation ratio is the number of $\mathrm{H}_{2} \mathrm{O}$ molecules transpired per $\mathrm{CO}_{2}$ molecule fixed and is an inefficiency index; plants with high $N$ values use water less efficiently than plants with low $N$.

Fig. 10 shows that water-use efficiency improves with increasing $C_{A}$ at constant $T_{A}$ for all $T_{A}$ in the case we have chosen. It also shows that for $C_{A} \gtrsim 12.5 \mathrm{nM} \mathrm{cm}^{-3}$ (normal air concentration), $N$ is almost independent of $T_{A}$ between 0 and $15^{\circ} \mathrm{C}$ at constant $C_{A}$. At all other $T_{A}$ and $C_{A}, N$ increases with $T_{A}$ at constant $C_{A}$. At $T_{A} \gtrless 35^{\circ} \mathrm{C}, T$ is above optimum for photosynthesis and $N$ increases rapidly with increasing $T_{A}$ until it approaches infinity at $T_{A} \cong 40.7^{\circ} \mathrm{C}$ (the air temperature at which $T=40^{\circ} \mathrm{C}$ and photosynthesis ceases). Finally, under the chosen conditions, the leaf uses water most efficiently at $T_{A}$ between 

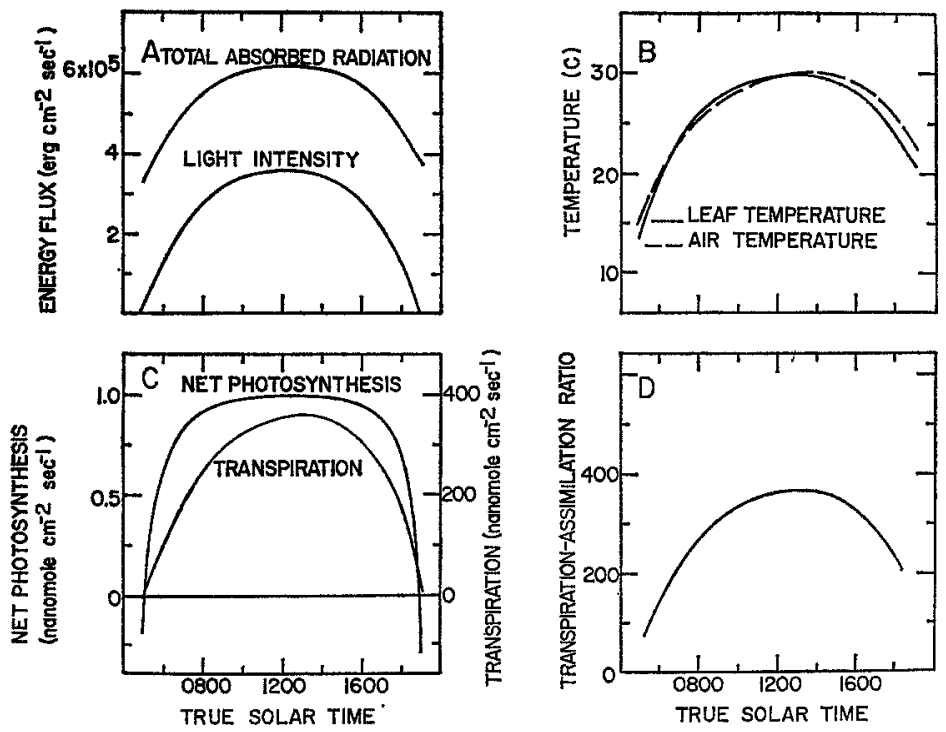

Fig. 11 A-D. Total absorbed radiation, light intensity, air temperature, leaf temperature, transpiration, net photosynthesis, and transpiration-assimilation ratio as a function of true solar time. Light intensity and air temperature in relation to true solar time are based on data in Fig. 78 of Geiger (1966) for a sunny day in mid-July in Palermo $\left(38^{\circ} 10^{\prime} \mathrm{N}\right)$. Relative humidity was calculated with the assumption that absolute humidity was constant throughout the day and r.h. was 0.40 at maximum $T_{A}$. Eqs. (9), (16) and (18) were used with values in Appendix A to calculate the remaining curves

approximately 5 and $25^{\circ} \mathrm{C}$ and $C_{A}=25 \mathrm{nM} \mathrm{cm}^{-3}$ (approximately twice atmospheric concentration). Values for $N$ vary from 155 to 170 in this regime.

Fig. $11 \mathrm{~A}-\mathrm{D}$ shows $L, Q_{A B S}, T_{A}, T, E, P_{1}$ and $N$ as functions of true solar time during the course of a hypothetical but typical day. Note that the net-photosynthesis curve (Fig. 11C) rises steeply in the early morning to a broad plateau maintained during most of the day and then declines steeply in the late afternoon. All of the other curves rise and fall more slowly and have a much less distinct plateau. This indicates that the various factors governing photosynthesis interact to maintain photosynthesis at a relatively high and unchanging level throughout most of the day even though the individual factors governing it change considerably. Water-use efficiency (Fig. 11D) is highest during the early morning and the late afternoon, while it is lowest in the early afternoon when $T$ is highest. Values of $N$ obtained around sunrise and sunset have been omitted. When $P_{1}$ passes through $P_{1}=0$ very large positive 


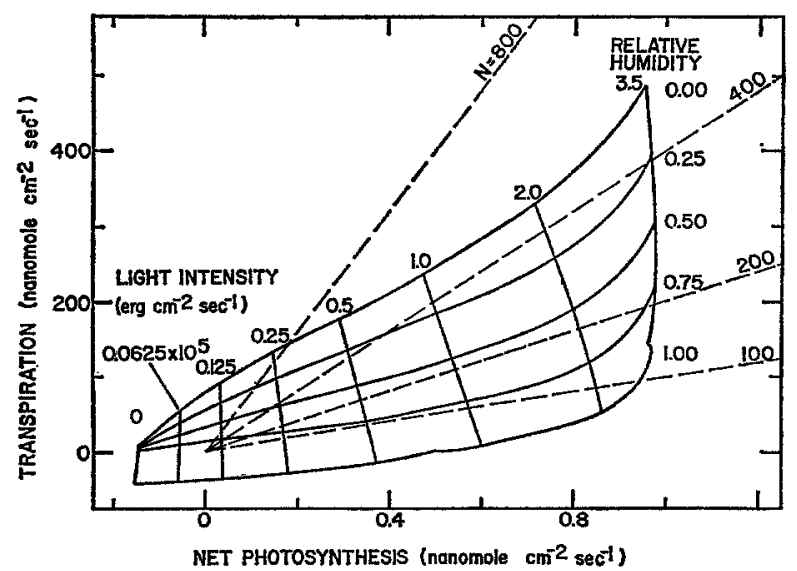

Fig. 12. Transpiration and net photosynthesis as functions of relative humidity and light intensity. Light intensity and $T_{A}$ were taken from the morning hours in Fig. Il A and B. Eqs. (9) and (16) were used with values in Appendix A

and negative values of $N$ result which are mathematically correct but physiologically meaningless.

Fig. 12 shows a grid of r.h. versus $L$ superimposed on $E$ versus $P_{1}$ axes. In most of the central area of the grid, $L$ has relatively little effect on water-use efficiency at constant r.h. In this region, i.e. between $L=0.5$ and $2.0 \times 10^{5} \mathrm{erg} \mathrm{cm}^{-2} \mathrm{~s}^{-1}$ and r.h. between 0 and 0.75 , increasing $L$ by $400 \%$ changes $N$ by no more than $35 \%$ along lines of constant r.h. At high $L\left(\gtrsim 3 \times 10^{5} \mathrm{erg} \mathrm{cm}^{-2} \mathrm{~s}^{-1}\right), N$ rises rapidly with increasing $L$. If values at still higher $L$ were plotted the whole grid would fold back toward the left, as the r.h. $=1.0$ line has already started to do, with the constant humidity lines pointing toward the upper left hand portion of the figure. At these $L$ values, $T$ exceeds the optimum for photosynthesis, and consequently $P_{1}$ decreases while $E$ continues to increase producing ever larger $N$. Negative $E$ indicates that water vapor is condensing on the leaf. The boundary layer resistance is the only resistance to water vapor diffusion for negative $E$ since water condenses primarily on the outside of the leaf. Thus for negative $E$ the stomatal resistance to water vapor diffusion, $r_{s}$, is deleted from Eq. (16). Negative $E$ results in negative $N$ if $P_{1}$ is positive. This occurs in Fig. 12 at r.h. $\cong 1.0$ and $L=0.1$ to $0.75 \times 10^{5} \mathrm{erg} \mathrm{cm}^{-2} \mathrm{~s}^{-1}$. In this case, negative $N$ indicates extreme water-use efficiency. Note the discontinuity in the slope of the r.h. $=1.0$ line at $E=0$. At this point, condensation is replaced by transpiration and the diffusion resistance to water vapor changes abruptly. 
We thank Drs. S. Moreshet and Hyrum B. Johnson for many helpful discussions. This work was supported in part by grants from the Ford Foundation and the U.S. Atomic Energy Commission.

\section{Appendix A}

Symbols, Definitions, Units, and Typical Values Used in all Calculations Unless Specified Otherwise in the Figure Captions

\begin{tabular}{|c|c|c|c|}
\hline Symbol & Definition & $\begin{array}{l}\text { Typical } \\
\text { Value }\end{array}$ & Units \\
\hline$A$ & Total surface area of leaf & & $\mathrm{cm}^{2}$ \\
\hline$A_{L}$ & Area exposed to long-wave incident flux & & $\mathrm{cm}^{2}$ \\
\hline$A_{S}$ & Area exposed to short-wave incident flux & & $\mathrm{cm}^{2}$ \\
\hline$\alpha_{L}$ & Long-wave absorptivity & 0.95 & \\
\hline$\alpha_{S}$ & Short-wave absorptivity & 0.50 & \\
\hline$B$ & $\begin{array}{l}\text { Dimension of the leaf perpendicular to } \\
\text { wind flow }\end{array}$ & 5 & $\mathrm{~cm}$ \\
\hline$C$ & Convective heat transfer & & $\mathrm{erg} \mathrm{cm^{-2 } \mathrm { s } ^ { - 1 }}$ \\
\hline$C_{A}$ & $\mathrm{CO}_{2}$ concentration in the free air & 12.5 at $25^{\circ} \mathrm{C}$ & $\mathrm{nM} \mathrm{cm}^{-3}$ \\
\hline$C_{C}$ & $\mathrm{CO}_{2}$ concentration in the chloroplasts & & $\mathrm{nM} \mathrm{\textrm {cm } ^ { - 3 }}$ \\
\hline$C_{I}$ & $\mathrm{CO}_{2}$ concentration in the IAS & & $\mathrm{nM} \mathrm{cm}-3$ \\
\hline$C_{W}$ & $\mathrm{CO}_{2}$ concentration at the sites of respiration & & $\mathrm{nM} \mathrm{\textrm {cm } ^ { - 3 }}$ \\
\hline$C_{O A}$ & $\begin{array}{l}\mathrm{O}_{2} \text { concentration in the air as a fraction } \\
(V / V)\end{array}$ & 0.25 & \\
\hline$D$ & Dimension of the leaf along the wind flow & 5 & $\mathrm{~cm}$ \\
\hline$d(T), d\left(T_{A}\right)$ & $\begin{array}{l}\text { Saturation density of water vapor at } T \text { and } \\
T \text {, respectively }\end{array}$ & & $\mathrm{nM} \mathrm{cm}^{-3}$ \\
\hline$E$ & Transpiration rate & & $\mathrm{nM} \mathrm{cm} \mathrm{cm}^{-2} \mathrm{~s}^{-1}$ \\
\hline$\varepsilon$ & Emissivity & 0.95 & \\
\hline$F(T)$ & $\begin{array}{l}F \text { as a function of } T \text {, a temperature } \\
\text { dependence of } W_{M}\end{array}$ & & \\
\hline$G(T)$ & $\begin{array}{l}G \text { as a function of } T \text {, a temperature } \\
\text { dependence of } P_{M} \text { and } K_{T}\end{array}$ & & \\
\hline$r$ & $\mathrm{CO}_{2}$ compensation concentration & & $\mathrm{nM} \mathrm{cm}^{-3}$ \\
\hline IAS & Intercellular air spaces & & \\
\hline$I_{S}$ & Short-wave incident flux $(\lambda<4 \mu \mathrm{m})$ & & $\mathrm{erg} \mathrm{cm}^{-2} \mathrm{~s}^{-1}$ \\
\hline$\tilde{K}$ & A constant equal to $C_{C}$ at which $P=P_{M} / 2$ & 10 & $\mathrm{nM} \mathrm{cm}^{-3}$ \\
\hline$K_{1}$ & $\begin{array}{l}\text { An empirically determined convection } \\
\text { coefficient }\end{array}$ & see text & \\
\hline$K_{2}$ & An empirically determined constant & see text & \\
\hline $\boldsymbol{K}_{L}$ & $L$ at which $P_{M}(L)=P_{M U} / 2$ & $1 \times 10^{5}$ & $\mathrm{erg} \mathrm{\textrm {cm } ^ { - 2 } \mathrm { s } ^ { - 1 }}$ \\
\hline$K_{R L}$ & Value of $L$ at which $R_{S}=2\left(\min R_{S}\right)$ & $3.5 \times 10^{4}$ & $\mathrm{erg} \mathrm{cm}^{-2} \mathrm{~s}^{-1}$ \\
\hline$K_{W P L}$ & $\begin{array}{l}\text { The M-M constant for the } L \text { dependence } \\
\text { of } W_{p} \text { numerically the same as } K_{L}\end{array}$ & $1 \times 10^{5}$ & $\mathrm{erg} \mathrm{cm}^{-2} \mathrm{~s}^{-1}$ \\
\hline$L$ & Light intensity $(400-700 \mathrm{~nm})$ & $4 \times 10^{5}$ & 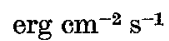 \\
\hline $\bar{L}_{H}$ & $\begin{array}{l}\text { A constant such that when } L=L_{H}, \\
\exp \left[(-\ln 2)\left(\frac{L}{L}\right)\right]=\frac{1}{2}\end{array}$ & $1 \times 10^{4}$ & $\mathrm{erg} \mathrm{cm}^{-2} \mathrm{~s}^{-1}$ \\
\hline$L_{v}$ & Latent heat of vaporization & & erg $n M^{-1}$ \\
\hline
\end{tabular}




\begin{tabular}{lll}
\hline Symbol Definition & $\begin{array}{l}\text { Typical Units } \\
\text { Value }\end{array}$ \\
\hline
\end{tabular}

$N \quad$ Number of water molecules transpired per $\mathrm{CO}_{2}$ molecule fixed

$$
M \quad=\frac{\left(W_{P L T O}\right) C_{O A}}{P_{M L T}} \quad 0.29 \text { at } C_{O A}=1
$$

M-M Michaelis-Menten

$Q_{A B S} \quad$ Absorbed radiation

$P \quad$ Gross photosynthesis

$P_{1} \quad$ Net photosynthesis $\left(\mathrm{CO}_{2}\right.$ flux through $\left.R_{1}\right)$

$P_{2}, P_{3}, P_{4} \quad \mathrm{CO}_{2}$ flux through $R_{2}, R_{3}$, and $R_{4}$ respectively

$P_{5} \quad$ Gross photosynthesis (rate of $\mathrm{CO}_{2}$ fixation in the chloroplasts)

$P_{M} \quad$ Gross photosynthesis at saturating $C_{C}$ for given $L$ and $T$

$P_{M L} \quad$ Gross photosynthesis at saturating $C_{C}$ and saturating $L$ for given $T$

$P_{M L T} \quad$ Gross photosynthesis at saturating $C_{C}$,

erg $\mathrm{cm}^{-2} \mathrm{~s}^{-1}$

$\mathrm{nM} \mathrm{cm} \mathrm{cm}^{-2} \mathrm{~s}^{-1}$

$\mathrm{nM} \mathrm{cm}^{-2} \mathrm{~s}^{-1}$

$\mathrm{nM} \mathrm{cm}{ }^{-2} \mathrm{~s}^{-1}$

$\mathrm{nM} \mathrm{cm} \mathrm{cm}^{-2} \mathrm{~s}^{-1}$ saturating $L$ and optimum $T$

RAD Radiation emitted

$R \quad$ Total resistance to $\mathrm{CO}_{2}$ diffusion

$R_{M} \quad$ Sum of all liquid phase resistances between the IAS and the chloroplasts

$R_{S} \quad$ Stomatal resistance to $\mathrm{CO}_{2}$

$\min _{S} R_{S} \quad$ Minimum value of $R_{S}$ reached at large $L$

$R_{1} \quad$ Boundary layer resistance plus stomatal resistance to $\mathrm{CO}_{2}$ difussion

$R_{2} \quad$ Direct resistance to $\mathrm{CO}_{2}$ diffusion between the IAS and the sites of photosynthesis

$R_{3} \quad$ Direct resistance to $\mathrm{CO}_{2}$ diffusion between the IAS and the sites of respiration

$R_{4} \quad$ Direct resistance to $\mathrm{CO}_{2}$ diffusion between the sites of photosynthesis and respiration

$r_{s} \quad$ Stomatal diffusion resistance to water vapor

r.h. Relative humidity as a number between 0 and 1

$\sigma \quad$ Stefan-Boltzmann constant

$T \quad$ Leaf temperature

$T_{A} \quad$ Air temperature

$\vec{V} \quad$ Wind speed

W Respiration

$W_{M} \quad$ "Mitochondrial respiration", the sum of the classical dark respiratory pathways

$W_{M L T} \quad W_{M}$ at zero $L$ and optimum $T\left(45^{\circ} \mathrm{C}\right)$

$W_{P} \quad$ "Peroxisomal respiration", the sum of the light induced respiratory pathways

$\mathrm{nM} \mathrm{cm} \mathrm{cm}^{-2} \mathrm{~s}^{-1}$

$\mathrm{nM} \mathrm{cm} \mathrm{c}^{-2} \mathrm{~s}^{-1}$

$\mathrm{nM} \mathrm{cm} \mathrm{m}^{-2} \mathrm{~s}^{-1}$

$\operatorname{erg} \mathrm{cm}^{-2} \mathrm{~s}^{-1}$

$\mathrm{s} \mathrm{\textrm {cm } ^ { - 1 }}$

$\mathrm{s} \mathrm{cm}-1$

$\mathrm{s} \mathrm{cm}-1$

$2.5 \quad \mathrm{~s} \mathrm{~cm}^{-1}$

$1.65+R_{S} \quad \mathrm{~s} \mathrm{~cm}^{-1}$

5

$\mathrm{s} \mathrm{cm}^{-1}$

5

$\mathrm{s} \mathrm{em} \mathrm{em}^{-1}$

1

$\mathrm{s} \mathrm{cm}^{-1}$

0.5

$\mathrm{s} \mathrm{cm}-1$

$5.67 \times 10^{-5} \quad \mathrm{erg} \mathrm{cm}^{-2} \mathrm{~s}^{-1}$

${ }^{\circ} \mathrm{K}^{-4}$

30

${ }^{\circ} \mathrm{C}$

${ }^{\circ} \mathrm{C}$

$\mathrm{cm} \mathrm{s}^{-1}$

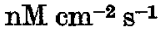

$\mathrm{nM} \mathrm{cm}{ }^{-2} \mathrm{~s}^{-1}$

$\mathrm{nM} \mathrm{cm} \mathrm{cm}^{-2} \mathrm{~s}^{-1}$

$\mathrm{nM} \mathrm{cm}^{-2} \mathrm{~s}^{-1}$

$W_{P L T O} \quad$ Value of $W_{P}$ at saturating $L$, optimum $T$, and $C_{O A}=1.0$ 


\section{Appendix B}

Derivation of Eq. (3), Photosynthesis for a Plant without Respiration

Solve Eq. (1) for $C_{C}$ and substitute into Eq. (2):

$$
P=\frac{P_{M}}{1+\frac{K}{C_{A}-R P}} .
$$

Rearrange (B.1) to eliminate all fractions and put all terms on one side of the equation:

$$
R P^{2}-\left(C_{A}+K+R P_{M}\right) P+C_{A} P_{M}=0 .
$$

This is now a quadratic in $P$ of the familiar form

$$
a x^{2}+b x+c=0
$$

the solutions of which are:

$$
x=\frac{-b \pm \sqrt{b^{2}-4 a c}}{2 a}
$$

Thus (B.2) has two solutions:

$$
P=\frac{\left(C_{A}+K+R P_{M}\right) \pm\left[\left(C_{A}+K+R P_{M}\right)^{2}-4 C_{A} R P_{M}\right]^{\frac{1}{2}}}{2 R} .
$$

To determine which solution is valid, we need to know that $P \rightarrow P_{M}$ as $C_{A} \rightarrow \infty$. For convenience in the following manipulations let the second term in the numerator of (B.3) be $Z$; i.e.

$$
Z=\left[\left(C_{A}+K+R P_{M}\right)^{2}-4 C_{A} R P_{M}\right]^{\frac{1}{2}} .
$$

Factor out $\left(C_{A}+K+R P_{M}\right)^{2}$ :

$$
Z=\left(C_{A}+K+R P_{M}\right)\left[1-\frac{4 C_{A} R P_{M}}{\left(C_{A}+K+R P_{M}\right)^{2}}\right]^{\frac{1}{2}}
$$

Expand using the binomial theorem:

$$
\begin{gathered}
Z=\left(C_{A}+K+R P_{M}\right)\left\{1-\frac{1}{2} \frac{4 C_{A} R P_{M}}{\left(C_{A}+K+R P_{M}\right)^{2}}+\frac{\frac{1}{2}\left(\frac{1}{2}-1\right)}{2 !}\right. \\
\left.\left[\frac{-4 C_{A} R P_{M}}{\left(C_{A}+K+R P_{M}\right)^{2}}\right]^{2}+\cdots\right\} .
\end{gathered}
$$

If $C_{A} \gg K$ and $C_{A} \gg R P_{M}$ then $\frac{C_{A} R P_{M}}{\left(C_{A}+K+R P_{M}\right)^{2}} \ll 1$ and successive terms in (B.6) will be smaller and smaller. For large enough $C_{A}, Z$ is quite well approximated by

$$
Z \cong\left(C_{A}+K+R P_{M}\right)\left(1-\frac{1}{2} \frac{4 C_{A} R P_{M}}{\left(C_{A}+K+R P_{M}\right)^{2}}\right)
$$

Now substitude (B.7) into (B.3):

$$
\begin{gathered}
P \cong \frac{\left(C_{A}+K+R P_{M}\right) \pm\left(C_{A}+K+R P_{M}\right)\left[1-\frac{4 C_{A} R P_{M}}{2\left(C_{A}+K+R P_{M}\right)^{2}}\right]}{2 R} \\
\text { Case I, taking + sign, } P \cong \frac{2\left(C_{A}+K+R P_{M}\right)-\frac{2 C_{A} R P_{M}}{\left(C_{A}+K+R P_{M}\right)}}{2 R}
\end{gathered}
$$




$$
\begin{aligned}
& \cong \frac{\left(C_{A}+K+R P_{M}\right)^{2}-C_{A} R P_{M}}{R\left(C_{A}+K+R P_{M}\right)} \\
& \lim _{C_{A} \rightarrow \infty} P=\frac{C_{A}^{2}-0}{R C_{A}} \rightarrow \frac{C_{A}}{R} .
\end{aligned}
$$

Case II, taking - sign,

$$
\text { As } \begin{aligned}
P & \cong \frac{2 C_{A} R P_{M}}{2 R\left(C_{A}+K+\bar{R} P_{M}\right)} . \\
\frac{C_{A}}{C_{A}+K+R P_{M}} & \rightarrow 1 \text { so } \\
\lim _{A \rightarrow \infty} P & =\lim _{C_{A \rightarrow \infty}} \frac{P_{M} C_{A}}{C_{A}+\bar{K}+R P_{M}}=P_{M} .
\end{aligned}
$$

Thus the minus sign is what we want and

as in Eq. (3).

$$
P=\frac{\left(C_{A}+K+R P_{M}\right)-\left[\left(C_{A}+K+R P_{M}\right)^{2}-4 C_{A} R P_{M}\right]^{\frac{1}{2}}}{2 R}
$$

\section{Appendix C}

Derivation of Eq. (9), Net Photosynthesis as a Function of $K, C_{A}, W, R_{1}$,

$$
R_{2}, R_{3} \text {, and } R_{4}
$$

A very important first assumption is that we have steady state conditions. Using the notation of Fig. 2, apply Fick's diffusion law across each of the four resistances:

$$
\begin{aligned}
& P_{1}=\frac{C_{A}-C_{I}}{R_{1}}, \\
& P_{2}=\frac{C_{I}-C_{C}}{R_{2}}, \\
& P_{3}=\frac{C_{W}-C_{I}}{R_{3}}, \\
& P_{4}=\frac{C_{W}-C_{C}}{R_{4}} .
\end{aligned}
$$

Also, the flux of $\mathrm{CO}_{2}$ diffusing away from any point in the circuit must equal the flux diffusing toward it. At the junction of resistances $R_{1}, R_{2}$, and $R_{3}$, we have

Similarly,

$$
P_{2}=P_{1}+P_{3} \text {. }
$$

$$
\begin{aligned}
& W=P_{3}+P_{4}, \\
& P_{5}=P_{2}+P_{4} .
\end{aligned}
$$

We now seek $P_{2}, P_{3}, P_{4}$ and $P_{5}$ in terms of $P_{1}$. If Eqs. (C.3) and (C.4) are rearranged:

and

$$
C_{W}=C_{I}+P_{3} R_{3}
$$

$$
C_{W}=C_{C}+P_{4} R_{4} \text {. }
$$

Equate right hand sides of Eqs. (C.8) and (C.9):

$$
C_{I}+P_{3} R_{3}=C_{C}+P_{4} R_{4} \text {. }
$$


If Eq. (C.2) is solved for $C_{C}$ and Eq. (C.6) for $P_{4}$ and substituted into (C.10):

$$
C_{I}+P_{3} R_{3}=\left(C_{I}-P_{2} R_{2}\right)+\left(W-P_{3}\right) R_{4} \text {. }
$$

Solve (C.5) for $P_{3}$, substitute into (C.11) and solve for $P_{2}$ :

then,

$$
\begin{gathered}
C_{I}+\left(P_{2}-P_{1}\right) R_{3}=C_{I}-P_{2} R_{2}+\left(W-P_{2}+P_{1}\right) R_{4}, \\
P_{2}=\frac{P_{1}\left(R_{3}+R_{4}\right)+W R_{4}}{R_{2}+R_{3}+R_{4}},
\end{gathered}
$$

and

$$
\begin{aligned}
& P_{3}=P_{2}-P_{1}=\frac{W R_{4}-P_{1} R_{2}}{R_{2}+R_{3}+R_{4}}, \\
& P_{4}=W-P_{3} \frac{W\left(R_{2}+R_{3}\right)+P_{1} R_{2}}{R_{2}+R_{3}+R_{4}}
\end{aligned}
$$

$$
P_{5}=P_{2}+P_{4}=\left(P_{1}+P_{3}\right)+\left(W-P_{3}\right)=P_{1}+W .
$$

Thus, if we know $P_{1}, W, R_{1}, R_{2}, R_{3}$, and $R_{4}$ we can find $P_{2}, P_{3}, P_{4}$ and $P_{5}$ using (C.13) through (C.16). The concentrations, $C_{I}, C_{W}$ and $C_{C}$ can then be found by rearranging and combining (C.1), (C.2) and (C.3):

and

$$
C_{X}=C_{A}-P_{1} R_{1} \text {, }
$$

$$
C_{W}=C_{I}+P_{3} R_{3}=C_{A}-P_{1} R_{1}+P_{3} R_{3}
$$

$$
C_{C}=C_{I}-P_{2} R_{2}=O_{A}-P_{1} R_{1}-P_{2} R_{2} \text {. }
$$

We now wish to include the M-M equation:

$$
P_{5}=\frac{P_{M}}{1+K / C_{C}} .
$$

First, substitute (C.13) into (C.19). After some rearrangement we get

where

$$
C_{C}=C_{A}-P_{1} S_{1}-W S_{2}
$$

and

$$
S_{1} \equiv R_{1}+\frac{R_{2}\left(R_{3}+R_{4}\right)}{R_{2}+R_{3}+R_{4}}
$$

$$
S_{2} \equiv \frac{R_{2} R_{4}}{R_{2}+R_{3}+R_{4}}
$$

Second, substitute (C.16) and (C.21) into (C.20):

Third, clear (C.24) of fractions:

$$
P_{1}+W=\frac{P_{M}}{1+\frac{K}{C_{A}-P_{1} S_{1}-W S_{2}}} .
$$

$$
\begin{aligned}
& S_{1} P_{1}^{2}- {\left[C_{A}+K+S_{1}\left(P_{M}-W\right)-W S_{2}\right] } \\
& P_{1}+\left(C_{A}-W S_{2}\right)\left(P_{M}-W\right)-W K=0 .
\end{aligned}
$$

This equation, a quadratic equation in $P_{1}$, is now handled in the same way as Eq. (B.7) in Appendix B. The only difference is that

$$
\lim _{c_{A} \rightarrow \infty} P_{1}=P_{M}-W
$$

where without respiration we had

$$
\lim _{C_{A} \rightarrow \infty} P=P_{M}
$$


The minus sign in the solution of the quadratic is again the sign we want and we finally get:

$$
\begin{array}{r}
P_{1}=\frac{\left[C_{A}+K+S_{1}\left(P_{M}-W\right)-W S_{2}\right]-\left\{\left[C_{A}+K+S_{1}\left(P_{M}-W\right)-W S_{2}\right]^{2}\right.}{2 S_{1}} \\
\frac{\left.-4 S_{1}\left[\left(C_{A}-W S_{2}\right)\left(P_{M}-W\right)-W K\right]\right\}^{\frac{1}{2}}}{2 S_{1}}
\end{array}
$$

\section{References}

Anderson, M. C.: Photon flux, chlorophyll content, and photosynthesis under natural conditions. Ecology 48, 1050-1053 (1967).

Bange, G. G. T.: On the quantitative explanation of stomatal resistance. Acta botanica neerl. 2, 255-297 (1953).

Björkman, O.: The effect of oxygen concentration on photosynthesis in higher plants. Physiol. Plant. (Cph.) 19, 618-633 (1966).

Blackman, F. F., Smith, A. M.: Experimental researches on vegetable assimilation and respiration. IX. On assimilation in submerged water-plants and its relation to the concentration of carbon dioxide and other factors. Proc. roy. Soc. B 85, $389-412$ (1911).

Bowes, G., Ogren, W. L.: The effect of light intensity and atmosphere on ribulose diphosphate carboxylase activity. Plant Physiol. 46, Suppl. 7 (1970).

Briggs, G. E., Haldane, J. B. S. : A note on the kinetics of enzyme action. Biochem. J. 19, 338-339 (1925).

Decker, J. P.: Comparative responses of carbon dioxide outburst and uptake in tobacco. Plant Physiol. 34, 100-102 (1959).

Ellyard, P. W., Gibbs, M.: Inhibition of photosynthesis by oxygen in isolated spinach chloroplasts. Plant Physiol. 44, $1115-1121$ (1969).

Fock, H., Egle, K.: Ửber die „Lichtatmung“ bei grünen Pflanzen. I. Die Wirkung von Sauerstoff und Kohlendioxyd auf den $\mathrm{CO}_{2}$-Gaswechsel während der Lichtund Dunkelphase. Beitr. Biol. Pflanzen 42, 213-239 (1966).

Forrester, M. L., Krotkov, G., Nelson, C. D.: Effect of oxygen on photosynthesis, photorespiration and respiration in detached leaves. I. Soybean. Plant Physiol. 41, 422-427 (1966).

Frederick, S. E., Newcomb, E. H.: Microbody-like organelles in leaf cells. Science 168, 1353-1355 (1969).

Gaastra, P.: Photosynthesis of crop plants as influenced by light, carbon dioxide, temperature, and stomatal diffusion resistance. Meded. Landbouwhogeschool Wageningen 59, No. 11 (1959).

Gates, D. M.: Energy, plants and ecology. Ecology 46, 1-13 (1965).

- Transpiration and leaf temperature. Ann. Rev. Plant Physiol. 19, 211-238 (1968).

- Johnson, H. B., Yocum, C. S., Lommen, P. W.: Geophysical factors affecting plant productivity. Proc. Int. Symp. Productivity of Photosynthetic Systems. Pt. II: Theoretical foundations of optimization of the photosynthetic productivity. Moscow, U.S.S.R. Sept. 1969 (in press).

- Tantraporn, W.: The reflectivity of deciduous trees and herbaceous plants in the infrared to $25 \mu$. Science 115, 613-616 (1952).

Geiger, R.: The climate near the ground (transl. from German Scripta Technica, Inc.). Cambridge, Mass.: Harvard Univ. Press 1966.

Heath, O. V. S.: The physiological aspects of photosynthesis. Stanford, Calif.: Stanford University Press 1969. 
Hew, Ch.-S., Krotkov, G., Canvin, D. T. : Determination of the rate of $\mathrm{CO}_{2}$ evolution by green leaves in light. Plant Physiol. 44, 662-670 (1969).

Hoch, G., Owens, O. v. H., Kok, B.: Photosynthesis and respiration. Arch. Biochem. 101, 171-180 (1963).

Hofstra, G., Hesketh, T. D.: Effects of temperature on the gas exchange of leaves in the light and dark. Planta (Berl.) 85, 228-237 (1969).

Folmgren, P., Jarvis, P. G.: Carbon dioxide efflux from leaves in light and darkness. Physiol. Plant. (Cph.) 20, 1045-1051 (1967).

Honert, T. H. van den: Carbon dioxide assimilation and limiting factors. Rec. Trav. bot. néerl. 27, 149-284 (1930).

Irvine, J. E.: Evidence for photorespiration in tropical grasses. Physiol. Plant. (Cph.) 28, 607-612 (1970).

Jackson, W. A., Volk, R. J.: Photorespiration. Ann. Rev. Plant Physiol. 21, 385-432 (1970).

Lake, J. V.: Respiration of leaves during photosynthesis. I. Estimates from an electrical analogue. Aust. J. biol. Sci. 20, 487-493 (1967).

Meidner, H., Mansfield, T. A.: Physiology of stomata. Maidenhead, England: MoGraw-Hill 1968.

Parkhurst, D. F., Duncan, P. R., Gates, D. M., Kreith, F.: Wind-tunnel modelling of convection of heat between air and broad leaves of plants. Agr. Meteorol. 5, 33-47 (1968).

Raschke, K.: Uోber die physikalischen Beziehnngen zwischen Wärmeübergangszahl, Strahlungsaustausch, Temperatur und Transpiration eines Blattes. Planta (Berl.) 48, 200-238 (1956).

- Temperature dependence of $\mathrm{CO}_{2}$ assimilation and stomatal aperture in leaf sections of Zea mays. Planta (Berl.) 91, 336-363 (1970).

Rastorfer, J. R., Higinbotham, N.: Rates of photosynthesis and respiration of the moss Bryum sandbergii as influenced by light intensity and temperature. Amer. J. Bot. 55, 1225-1229 (1968).

Saitoh, M., Narita, K., Isikawa, S.: Photosynthetic nature of some aquatic plants in relation to temperature. Bot. Mag. Tokyo 88, 10-12 (1970).

Samish, Y., Koller, D.: Photorespiration in green plants during photosynthesis estimated by use of isotopic $\mathrm{CO}_{2}$. Plant Physiol. 43, 1129-1132 (1968).

Swinbank, W. C.: Long-wave radiation from clear skies. Quart. J. roy. Met. Soc. 89, 339-348 (1963).

Tregunna, E. B., Krotkov, G., Nelson, C. D.: Effect of oxygen on the rate of photorespiration in detached tobacco leaves. Physiol. Plant. (Cph.) 19, 723-733 (1966).

Turner, J. S., Brittain, E. G.: Oxygen as a factor in photosynthesis. Biol. Rev. 37, 130-170 (1962).

Vogel, S.: Convective cooling at low airspeeds and the shapes of broad leaves. J. exp. Bot. 21, 91-101 (1970).

Waggoner, P. E.: Predicting the effect upon net photosynthesis of changes in leaf metabolism and physics. Crop Sci. 9, 315-321 (1969).

Warburg, 0.: Utber die Geschwindigkeit der photochemischen Kohlensäurezersetzung in lebenden Zellen. Biochem. Z. 100, 230-270 (1919).

Zelitch, I.: Stomatal control. Ann. Rev. Plant Physiol. 20, 329-350 (1969).

P. W. Lommen

Missouri Botanical Garden

2315 Tower Grove Avenue

St. Louis, Missouri 63110, U.S.A. 